ISAHP Article: A Style Guide for Individual Papers To Be Submitted to the International Symposium of the Analytic Hierarchy Process 2020, Web Conference.

\title{
LAYOUT ASSESSMENT WITH STRUCTURING AND MATHEMATICAL MODELING BY THE AHP METHOD
}

\begin{abstract}
This present paper describes the decision processes with AHP method to choose between two alternatives that could improve the production performance of a galvanized duct manufacturing company. Its manufacturing line layout appears to be the constraints of production to attend the market demand. After structuring and analyzing the preferences and values under a criteria set evaluation, the most favorable layout promises to deliver cost reduction, technology improvement and better production performance. Although the web computational platform 3 Decision Methods (3decisionmethods.com) supported the problem modeling, the analysis is described with all axiomatic processes with details.
\end{abstract}

Keywords: AHP method, Industrial layout analysis, Cost reduction.

\section{Introduction}

Considering the technological advances obtained in the last decades and the need for man to achieve the personal and social interests, he was motivated to the development of devices and manufacturing processes in search to achieve his goals in a simple way. In this context, the company STEEL S/A, a fictitious name for study purposes, operates manufacturing galvanized steel ducts. Considering the need to meet the market demand, regarding the process of galvanized ducts, it was observed a bottleneck in one of these manufacturing lines, relative to the production of fixatives used in the painting process of ducts. In this case, the production restriction contributed to the generation of queues in the lines of the process, causing non-fulfillment of demands, increased costs, and loss of market.

The analysis of production layouts and manufacturing lines can be understood as a key point for a company to remain competitive in the market. Considering this factor, the paper addresses a case study based on the analysis of two types of layouts for implementation at STEEL S/A, in search to identify the most favorable solution regarding make possible the reduction of bottlenecks, achieve the market demand, and due to some possibilities, reduce the costs. As a way of supporting the analysis, the AHP method (Analytic Hierarchy Process) will work as a base to the analysis structure considering the multiples variables of influence and alternatives for implementation.

\section{Literature Review}

A problem occurs when the current state of a situation is different from the desired. An opportunity occurs when circumstances offer to a person, group, or organization a chance to exceed its objectives and goals. As presented by Almeida et al. (2015), Multiple Criteria Decision Analysis (MCDA) is the Operational Research field that allows the structuring and understanding of a problem in complex environments, considering risk and uncertainty, transparently, assisting in obtaining answers to problematics of varied natures.

In this scenario, the AHP method works supporting the decision-making process where they are not structured (SANTOS; GOMES; OLIVEIRA, 2016). According to Turban, Mclean, \& Wetherbe (1996), unstructured decisions are vague processes and complex problems, where human intuition provides such solutions. The AHP method consists of a mathematical model developed by Thomas L. Saaty in the 70s. The model allows a value judgment based on the use of a specific scale, for standardization and the inherent 
subjectivity of the use of qualitative variables, based on a verbal dig of value, also known as the fundamental Saaty scale (SAATY, 2008).

\section{Hypotheses / Objectives}

The analysis delimits the evaluation of the manufacturing line of fixatives for application to the production of metal ducts. Currently, the production line operates with only $54 \%$ of its predetermined daily capacity ( $\underline{8000}$ units produced out of 13714 projected), resulting in non-fulfillment of demands and delays in deliveries.

In this context, the company STEEL S/A adopted as a hypothesis the updating of its manufacturing line layout relative to fixatives production considered a bottleneck in the respective manufacturing process. Considering two types of layouts to be implemented both of them will be evaluated under a set of five criteria in search to achieve the company's objectives.

\section{Case Study}

Considering the analysis model based on the AHP method and verifying their relevance by observing the restrictions at the factory, were conducted interviews with experts in the industry itself and after these interviews and observations, was defined a set of five criteria, where three of these performing quantitative data and two evaluating in qualitative nature based on the scale proposed by Saaty. The criteria set is detailed in table 1 .

Table 1 - Criteria descriptions

\begin{tabular}{|c|c|c|}
\hline Criteria & Type & Description \\
\hline $\begin{array}{l}\text { Cost of } \\
\text { implementation }\end{array}$ & Quantitative & $\begin{array}{l}\text { Value analyzed for the implementation of the } \\
\text { manufacturing line. }\end{array}$ \\
\hline Production & Quantitative & $\begin{array}{l}\text { Production capacity expected for each layout after the } \\
\text { improvements applied. }\end{array}$ \\
\hline Cost reduction & Quantitative & $\begin{array}{l}\text { Expected cost reduction according to the type of } \\
\text { layout to be implemented, considering electrical } \\
\text { consumption and material transformation process. }\end{array}$ \\
\hline $\begin{array}{l}\text { Material } \\
\text { handling }\end{array}$ & Qualitative & $\begin{array}{l}\text { Criterion defined due to the reduction of material } \\
\text { movement according to the application of the defined } \\
\text { arrangement. }\end{array}$ \\
\hline Process quality & Qualitative & $\begin{array}{l}\text { The quality is due to the technical assistance for the } \\
\text { painting being done in perfect conditions. }\end{array}$ \\
\hline
\end{tabular}

In search to obtain the achievement of the strategic objective, two types of layouts, detailed in table 2, are evaluated under five types of criteria, already with their respective weights. The evaluation matrix and evaluating process are detailed in section 7, representing the preference inputs obtained by realized interviews with the Maintenance Manager and Manufacturing Engineer. For the AHP implementation, was utilized the web platform 3DM 3decisionmethods.com (BOZZA et al., 2020), exposed in figure 1, enabling to perform all the mathematical procedures. 
ISAHP Article: A Style Guide for Paper Proposals To Be Submitted to the International Symposium on the Analytic Hierarchy Process 2020, Web Conference.

Table 2 - Description of layouts

\begin{tabular}{|c|l|}
\hline Layouts & \multicolumn{1}{|c|}{ Description } \\
\hline \multirow{2}{*}{ A } & $\begin{array}{l}\text { The fixator line heating } 230^{\circ} \mathrm{C} \text { along a } 21 \mathrm{~m} \text { course before paint, after the } \\
\text { painting, the fixer enters the oven again for the curing process, realizing the } \\
\text { drying and homogenization of the epoxy powder, heating } 230^{\circ} \mathrm{C} \text { and traveling } \\
54.5 \mathrm{~m} \text {. Layout A features a production of } 17389 \text { units per day, a line speed of } \\
4.8 \mathrm{~m} / \mathrm{min} \text {, an estimated investment of } \mathrm{R} \$ 200,000.00 \text {, and a prospective cost } \\
\text { reduction of } \mathrm{R} \$ 420,000.00 \text { in one year. }\end{array}$ \\
\hline $\mathrm{B}$ & $\begin{array}{l}\text { The fixator line heating } 260^{\circ} \mathrm{C} \text {, the screw or nut would travel a total path of } \\
\text { 94.1m, being 30.3m before painting and 50.8m after painting, providing correct } \\
\text { curing and maintaining the quality standard. Layout B has a production of } 28257 \\
\text { units per day, a line speed of } 7.8 \mathrm{~m} / \text { min, polymerization time of } 6.5 \mathrm{~min}, \text { an } \\
\text { estimated investment of } \mathrm{R} \$ 300,000.00, \text { and a prospective cost reduction of } \mathrm{R} \\
\$ 360,000.00 \text { in one year. }\end{array}$ \\
\hline
\end{tabular}

After the assessment, it was possible to identify layout B as the most favorable alternative regarding the preferences and variables defined by the company. The respective layout expects an improvement to the new manufacturing line, providing a relative adaption to the market demands and technological update required.

Regarding the future values to be achieved, even presenting a higher cost of implementation, the layout B can provide favorable returns, by the revenue increase, considering the complete fulfillment of demands, cost reduction, and an increase of its productive capacity to 28257 fixatives per day, prospecting an increase of $106 \%$ relative to the previously programmed capacity (13741 units), or $253 \%$, considering the current produced (8000 units).

\section{Conclusions}

In a substantiated way, the implementation of the method made possible an extended analysis of the problem in context. After observing the problematic, collecting data, proposing improvement, and implementing the mathematical model as a solution tool, it was possible to indicate the most favorable alternative as a way of solution regarding the preferences and requirements stipulated by the company for the given problem.

The axiomatic model used logically demonstrates the most favorable alternative to implement, indicating the most appropriate investment for the return provided by cost reduction and increased productivity and quality in manufacturing processes. This application proves that decision support methodologies help small, medium, and large companies to better define their day-to-day strategies, in a logical and reasoned way, because Operational Research is for everyone.

\section{Key References}

ALMEIDA AT, CAVALCANTE CAV, ALENCAR MH, FERREIRA RJP, DE ALMEIDA-FILHO AT, GARCEZ TV. Multicriteria and Multiobjective Models for Risk, Reliability and Maintenance Decision Analysis. 1st ed. Springer; 2015.

BOZZA, Gabriel; RUY, Milena Mayara; SANTOS, Marcos dos; MOREIRA, Miguel Ângelo Lellis; ROCHA JUNIOR, Claudio de Souza; GOMES, Carlos Francisco Simões. Three Decision Methods (3DM) Software Web (v.1). 2020.

SAATY, Thomas L. Decision making with the analytic hierarchy process. Int. J. Services Sciences, v. 1, n.1, 83-98. 2008. 
ISAHP Article: A Style Guide for Paper Proposals To Be Submitted to the International Symposium on the Analytic Hierarchy Process 2020, Web Conference.

SANTOS, Marcos; GOMES, Carlos Francisco Simões; OLIVEIRA, Altina Silva. UMA ABORDAGEM MULTICRITÉRIO PARA SELEÇÃO DE UM NAVIO DE GUERRA DE MÉDIO PORTE A SER CONSTRUÍDO NO BRASIL.

TURBAN, Efraim.; MCLEAN, Ephraim.; WETHERBE, James. Information Technology for Management: Improving Quality and Productivity. New York: John Wiley and Sons. 1996.

\section{Appendices}

In this section is presented all numerical evaluation regarding to the case study approached in the section 4.

Table 2 - Matrix evaluation

\begin{tabular}{|c|c|c|}
\hline Criteria & Layout A & Layout B \\
\hline Cost of implementation & $\mathrm{R} \$ 200000.00$ & $\mathrm{R} \$ 300000.00$ \\
\hline Production & 17389 units & 28257 units \\
\hline Cost reduction & $\mathrm{R} \$ 420000.00 /$ year & $\mathrm{R} \$ 360000.00 /$ year \\
\hline Material handling & low need for movement & high need for movement \\
\hline Process quality & Average & High \\
\hline
\end{tabular}

Table 3 - Evaluation procedure in quantitative criteria - AHP

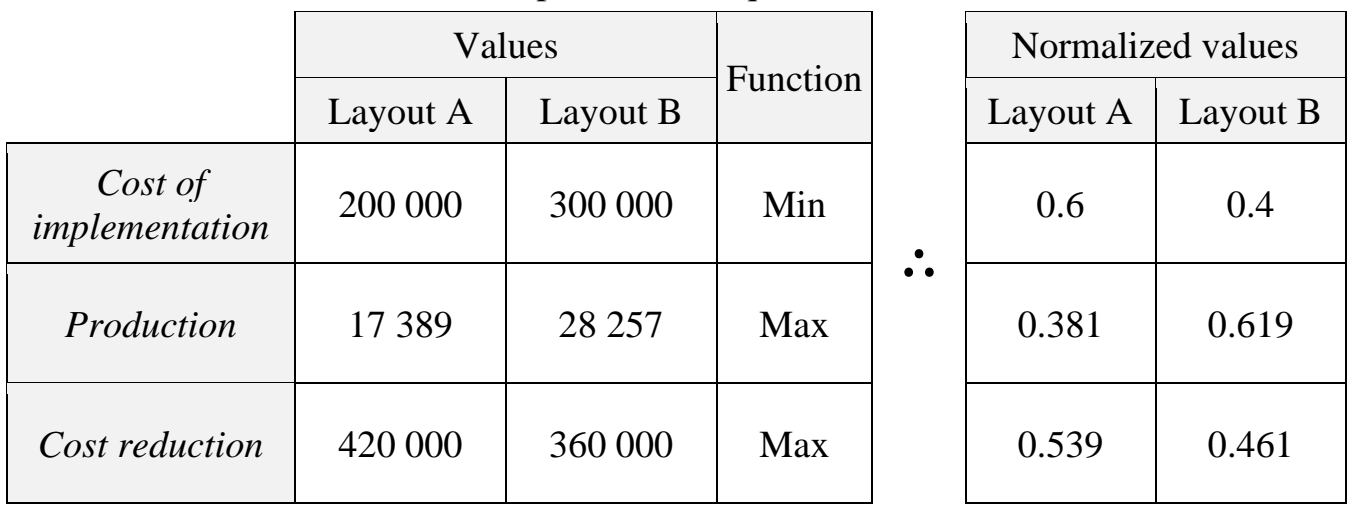

Table 4 - Evaluation procedure in criterion Material handling - AHP

\begin{tabular}{|c|c|c|c|c|c|c|c|}
\hline Material handling & Layout A & Layout B & \multirow{3}{*}{$\therefore$} & Layout A & Layout B & \multirow{3}{*}{$\therefore$} & $\begin{array}{l}\text { Normalized } \\
\text { punctuation }\end{array}$ \\
\hline Layout A & 1 & 5 & & 0.833 & 0.833 & & 0.833 \\
\hline Layout B & $1 / 5$ & 1 & & 0.167 & 0.167 & & 0.167 \\
\hline
\end{tabular}

Table 5 - Evaluation procedure in criterion Process quality - AHP

\begin{tabular}{|r|c|c|c|c|c|}
\hline Process quality & Layout A & Layout B & & Layout A & Layout B \\
\hline Layout A & 1 & $1 / 3$ \\
\hline Layout B & 3 & 1 \\
\hline
\end{tabular}$\quad \therefore$\begin{tabular}{|c|c|c|}
\hline $\begin{array}{c}\text { Normalized } \\
\text { punctuation }\end{array}$ \\
\hline 0.25 & 0.25 \\
\hline 0.75 & 0.75 \\
\hline
\end{tabular}$\quad \therefore$\begin{tabular}{|c|c|c|}
0.75 \\
\hline
\end{tabular}


ISAHP Article: A Style Guide for Paper Proposals To Be Submitted to the International Symposium on the Analytic Hierarchy Process 2020, Web Conference.

Table 6 - Evaluation procedure for criteria - AHP

\begin{tabular}{|r|c|c|c|c|c|}
\cline { 2 - 6 } \multicolumn{1}{c|}{} & $\begin{array}{c}\text { Cost of } \\
\text { implementation }\end{array}$ & Production & $\begin{array}{c}\text { Cost } \\
\text { reduction }\end{array}$ & $\begin{array}{c}\text { Material } \\
\text { handling }\end{array}$ & $\begin{array}{c}\text { Process } \\
\text { quality }\end{array}$ \\
\hline Cost of implementation & 1 & $1 / 4$ & $1 / 2$ & 1 & $1 / 3$ \\
\hline Production & 4 & 1 & 2 & 7 & 1 \\
\hline Cost reduction & 2 & $1 / 2$ & 1 & 2 & $1 / 2$ \\
\hline Material handling & 1 & $1 / 7$ & $1 / 2$ & 1 & $1 / 5$ \\
\hline Process quality & 3 & 1 & 2 & 5 & 1 \\
\hline
\end{tabular}

\begin{tabular}{|l|l|l|}
\hline$\lambda=5,094$ & Consistence Index $=0,0235$ & Consistence ratio $=0,0210$ \\
\hline
\end{tabular}

Table 7 - Aggregation process - AHP

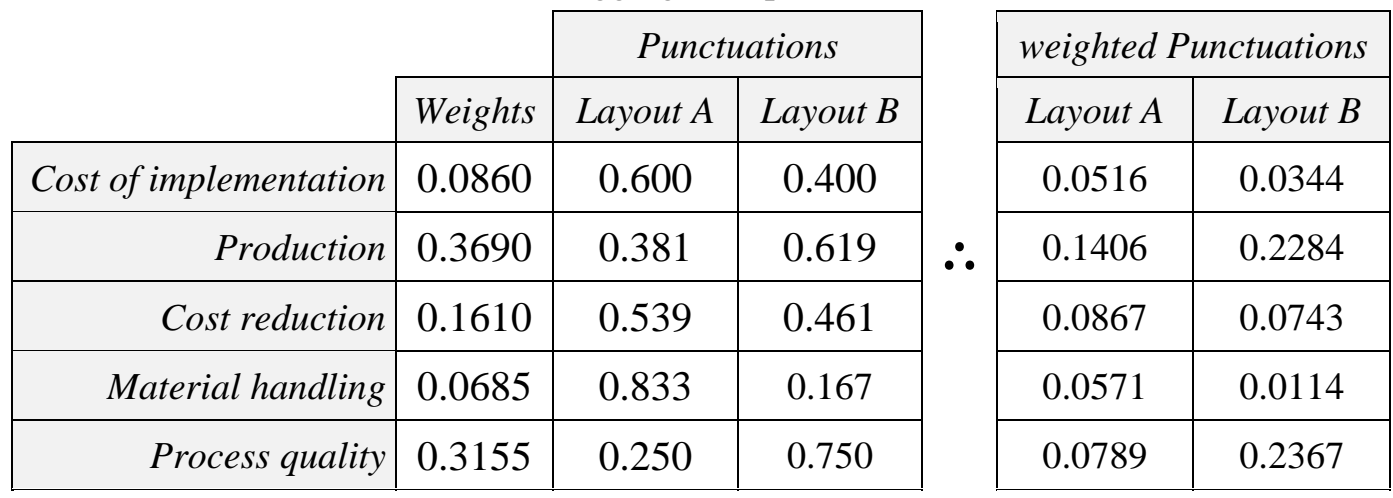

\begin{tabular}{|l|l|l|}
\hline Final Punctuation & 0.4148 & 0.5852 \\
\hline
\end{tabular}

Figure 1 - Computational web platform 3 Decision Methods

$\leftarrow \rightarrow C \quad \Delta$ Não seguro | 3decisionmethods.com/3DM/index.html

* BM

is $\theta$

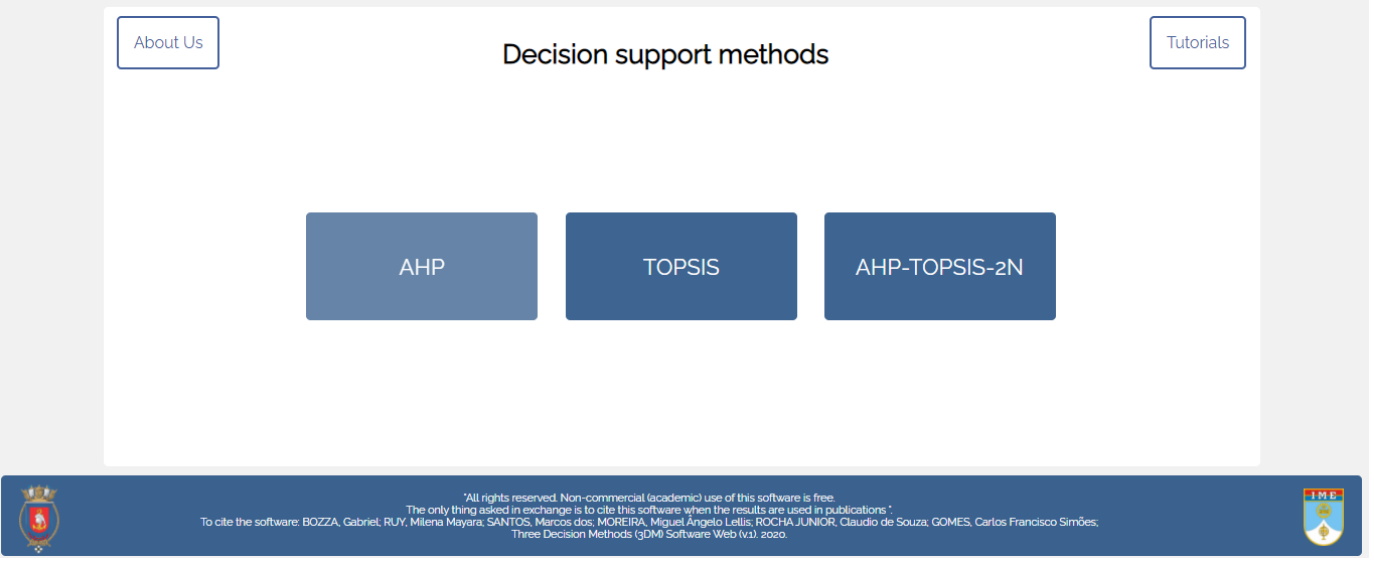

Decision support methods

$\theta \frac{N \mathbb{N}}{\pi \mathbb{N}}$ 